\title{
Delayed Reconstruction of the Eyelids After War Injuries: Experience from Lebanon (Report of 6 cases)
}

Ghassan S Abu-Sitta ${ }^{1}$, Riad Ma'luf ${ }^{2}$, Joe Baroud ${ }^{3}$, Rawad Chalhoub ${ }^{3^{*}}$, Christopher Hakim ${ }^{3}$ and Ramzi Maluf $^{3}$

${ }^{1}$ Department of Surgery, American University of Beirut Medical Center, Maamari Street Bayrut, Lebanon

${ }^{2}$ Department of Ophthalmology, American University of Beirut Medical Center, Maamari street Bayrut, Lebanon

${ }^{3}$ Department of Plastic and Reconstructive Surgery, American University of Beirut Medical Center, Maamari Street Bayrut, Lebanon

*Corresponding author: Rawad Chalhoub, Research Fellow, Department of Plastic and Reconstructive Surgery, American University of Beirut Medical Center, Maamari Street Bayrut, Lebanon, Tel: +96170133789; E-mail: Rsc06@aub.mail.edu

Rec date: January 24, 2018; Acc date: February 19, 2018; Pub date: February 21, 2018

Copyright: @ 2018 Abu-Sitta GS, et al. This is an open-access article distributed under the terms of the creative commons attribution license, which permits unrestricted use, distribution, and reproduction in any medium, provided the original author and source are credited.

\begin{abstract}
Introduction: War injured patients from Syria are constantly being transferred to Lebanon for management after rudimentary primary closure of their wounds is done at the combat zone.

Case presentation: The cases presented below represent some of the extreme cases of delayed presentation of peri-ocular trauma and the adaptations reconstructive surgeons had to make for conventional techniques.

Conclusion: We describe in our paper modified techniques in reconstructing delayed presentations of peri-ocular injuries secondary to war trauma in Lebanon and Syria.
\end{abstract}

Keywords: War trauma; Periocular trauma; Eyelid reconstruction; Delayed orbital reconstruction; Secondary reconstruction; Conflict zone; Middle East

\section{Introduction}

Although blast injuries have usually been the turf of military surgeons, in some parts of the world, plastic surgeons must be accustomed to have good knowledge and skill in the management of these injuries as they are encountered more often than in other locations.

The Middle East has become an area where war is an endemic disease. With the destruction of infrastructures and medical systems in the surrounding countries, war-injured patients are constantly being transferred to Lebanon for management. The Fragmentation from bombs, artillery shells and grenades along with flying foreign material may result in severe ocular and peri-ocular injury [1-3].

Orbital defects resulting from such injuries can present a significant challenge to the reconstructive surgeon because of surrounding tissue destruction and compromise, secondary scaring and tissue contraction, in addition to the limited financial recourses available in most cases. The peri-ocular region is highly vascular and rarely gets infected when adequately addressed.

However, highly contaminated wounds in combination with hardware insertion exponentially increase the risk of infection and the outcomes are usually disastrous [4,5]. Our management plan gives priority to correction of the external deformities as much as possible in order to allow fitting an aesthetically acceptable ocular prosthesis. We aim to describe various methods of reconstructing the peri-ocular area after the delayed presentation of complicated orbital injuries well beyond the golden period of surgical reconstruction.

\section{Materials and Methods}

Six patients were treated with local flaps for eyelid and canthal defects resulting from war-related trauma. All of our patients were injured in war zones and had rudimental primary closure and treatment for their injuries. None of the patients in our study were heavy smokers or had any radiation to the face that would affect wound healing. All our patients were treated with intravenous amoxicillin for three to four days during their inpatient stay and continued on $\mathrm{PO}$ amoxicillin for 2 weeks following discharge.

\section{Clinical Report}

\section{Case 1: Upper eyelid}

Our first case describes a 26-year-old male presenting 3 week after sustaining a blast injury to the mid-face (Figure 1A). Initial management consisted of complete obliteration of the orbital socket by suturing the lower eyelid superiorly to the eyebrow lower margin in an outside hospital. Upon further exploration in our center, most of the upper eyelid was found to be missing as well as an injured cornea and prolapsed uveal tissue. The uveal tissue was debrided, and alcohol was applied (Figure 1B). A $20 \mathrm{~mm}$ sphere was inserted into the resulting pocket and scleral tissue was sutured on top.

A superiorly based cheek myocutaneous flap was fashioned and rotated to reconstruct the missing upper lid tissues (Figures 1C and 1D). The flap was sutured to the adjacent eyebrow tissue using deep sutures of 5-0 vicryl and the skin was sutured with 6-0 nylon (Figure $1 \mathrm{E})$. The patient showed no complications post-operatively as there were no vascular compromise of the tip of the flap and no epidermolysis (Figure 1E). This flap was chosen as opposed to a Fricke flap as the temporal forehead area was severely scarred and hence compromised vascularity. A glabellar flap was not an option as well 
Citation: Abu-Sitta GS, Ma'luf R, Baroud J, Chalhoub R, Hakim C, et al. (2018) Delayed Reconstruction of the Eyelids After War Injuries: Experience from Lebanon (Report of 6 cases). J Trauma Treat 7: 415. doi:10.4172/2167-1222.1000415

Page 2 of 5

due to the large size of the defect for which this flap would not have provided proper coverage. The cheek flap is more malleable with better color match and the flap tip was well vascularized, despite the large length to width ratio, due to designing a thicker flap with muscle in its proximal aspect [6]. Three months later, the patient presented for medial canthal reconstruction. Figure $1 \mathrm{~F}$ shows the patient after fitting the prosthesis.

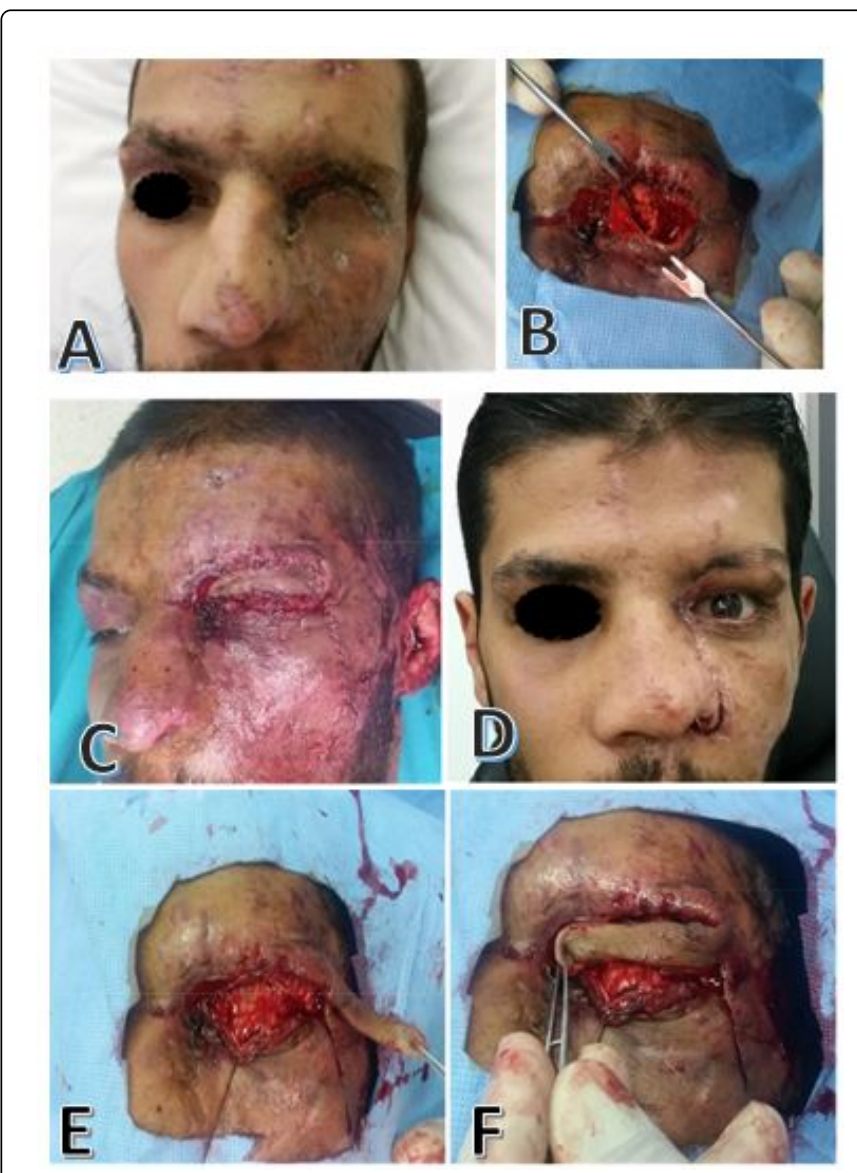

Figure 1: Upper eyelid injury: (A) Initial presentation 3 weeks after blast injury to the left midface managed by primary closure of the lower eyelid to the remaining upper eyelid tissue; (B) Initial exploration, revealing corneal penetration and uveal tissue prolapse which were debrided, and a spacer inserted. Superiorly-based myofacio-cutaneous cheek flap; (C) After elevation; (D) After rotation; (E) Immediate post-operative result; (F) 4 months post-operatively after medial canthal reconstruction (technique described in case 3 ) and ocular prosthesis fitting.

\section{Case 2: Lower eyelid}

This is a case of a 34-year-old male presenting 6 months after a blast injury to the right midface with resultant globe and extensive soft tissue loss (Figure 2A). Initial management consisted of serial debridements and dressing changes after which the patient presented with severe scaring and retraction of both upper and lower eyelids. On presentation to our center he had medial canthal dystopia with an inadequate lower fornix. The globe had been already enucleated leaving an anophthalmic socket. Surgical intervention involved complete medial canthal liberation and suspension (as described in case 3). For lower eyelid repair we decided to perform cheek myocutaneous rotation flap (Figures $2 \mathrm{~B}$ and $2 \mathrm{C}$ ) to replace the lower eyelid tissue deficiency, and a hard palate mucosal graft for structural support and inner lining (Figure 2B) [7]. 5-0 vicryl was used for the deep sutures and 6-0 nylon for the skin. The choice regarding the flap was dictated to us by the scarcity of healthy unscarred tissue in the upper eyelid, which prevented us from performing a Tripier flap [8].
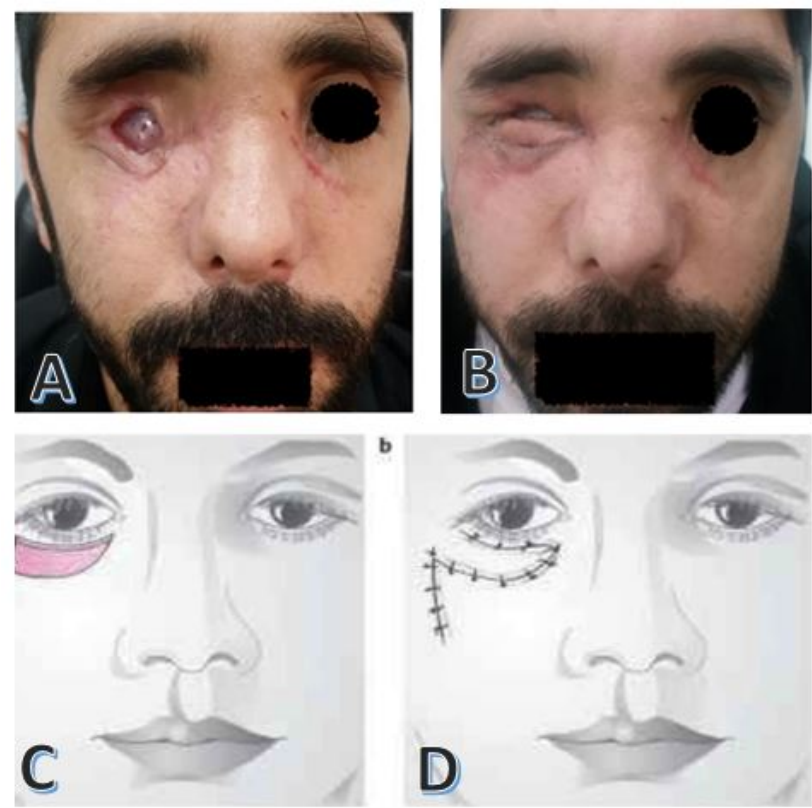

Figure 2: Lower eyelid injury: (A) Initial presentation of a 34-yearold man who sustained a blast injury to the right midface after 6 months after his initial injury with medial canthal dystopia, telecanthus, and an anophthalmic socket with inadequate lower fornix. (B) Post-operative images after complete medial canthal liberation and suspension (described in case 3), (C) Depiction of the myocutaneous flap used (reproduced from http:// www.europeanmedical.info/about/).

\section{Case 3: Medial canthus}

A 31-year-old male who presented one year after suffering a blast injury to the right mid-face. His initial management consisted of placement of a titanium mesh for anterior maxillary wall reconstruction that was complicated by an exudative infection. (Figures $3 \mathrm{~A}$ and $3 \mathrm{~B}$ ). Removing the titanium mesh and irrigating the site with saline treated the infection. A cheek rotation flap was advanced to cover the resulting defect (Figures $3 \mathrm{C}$ ). The decision was made to reconstruct the lower eyelid first, as it had priority to the upper eyelid in this case, since it will be the main support for the ocular prosthesis. The patient also developed severe medial canthal dystopia with inadequate lower fornix, after soft tissue coverage of the anterior maxillary wall (Figure 3C). An upper to lower eyelid transpostion flap or Tripier flap was used to repair the lower eyelid and creat a lower fornix for ocular prothesis support (Figure 3D).

Intra-operatively, the medial canthus was totally freed and mobilized superiorly. The technique of wiring we used is shown in 
Citation: Abu-Sitta GS, Ma'luf R, Baroud J, Chalhoub R, Hakim C, et al. (2018) Delayed Reconstruction of the Eyelids After War Injuries: Experience from Lebanon (Report of 6 cases). J Trauma Treat 7: 415. doi:10.4172/2167-1222.1000415

Page 3 of 5

Figure 3E. The medial canthal area is exposed bluntly using a fine mosquito clamp at a point posterior to the lacrimal crest. Two holes, vertically spaced $1 \mathrm{~cm}$ apart, are then made in the lacrimal fossa using an 18-gauge needle. A double armed 4-0 prolene suture is then passed through, the way shown in Figure 3E and then used to fix the medial canthal tissues. Figure $3 \mathrm{~F}$ shows the patient one-month post medial canthal reconstruction and lower eyelid reconstruction.

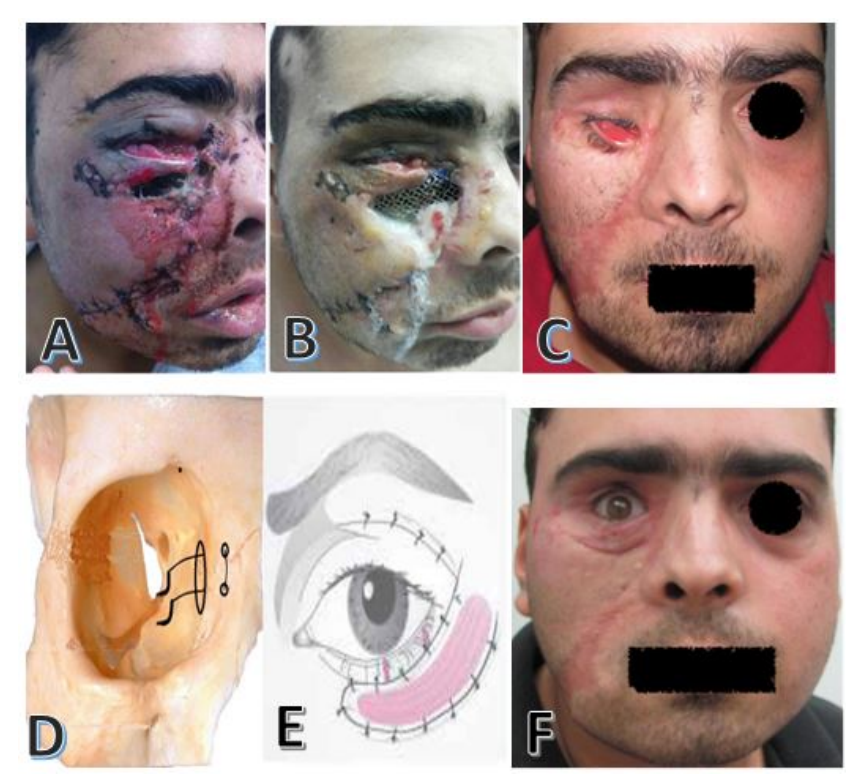

Figure 3: Medial canthal injury: (A) Delayed presentation of eyelid blast injury with severe scarring of both upper and lower eyelids and medial canthal displacement with anterior maxillary wall fracture; (B)Exudative infection of the titanium mesh used to reconstruct the maxillary wall (C) After cheek rotation flap to cover the anterior maxillary wall and development of severe medial canthal dystopia (D) Our preferred technique in medial canthal suspension using prolene sutures poses less risk of iatrogenic injury to the contralateral solely functioning eye and is less expesive than plates and screws in this limited resource scenario; (E) Depiction of the superomedially based upper eyelid myocutaneous flap used to reconstruct the lower eyelid or the Tripier flap (reproduced from http://www.europeanmedical.info/about/). (F) Post-operative results 1 month after medial canthal release and re-suspention, and upper eyelid myocutaneous flap (Tripier) transfer to the lower eyelid.

\section{Case 4: Lateral canthus}

A 32-year-old male presenting one year after his initial injury with lateral canthal dystopia and lower lid retraction (Figure 4A). He underwent mid-face lifting and lateral canthal mobilization to a more cephalic position. Figure $4 \mathrm{~B}$ shows the proper lateral canthal position after surgery. Our preferred method of lateral canthus fixation in war injuries is by creating a single hole in the thinner part of the lateral orbital wall, posterior to the thick orbital rim, using an 18-gauge needle. A 4-0 double-armed suture is then used to grasp the lateral canthal tissues, exiting from the hole and sutured to the temporalis muscle fascia (Figure 4C) [9]. This results in a firmer more durable attachment of the lateral canthus than when it is sutured to the periosteum of the lateral orbital rim.

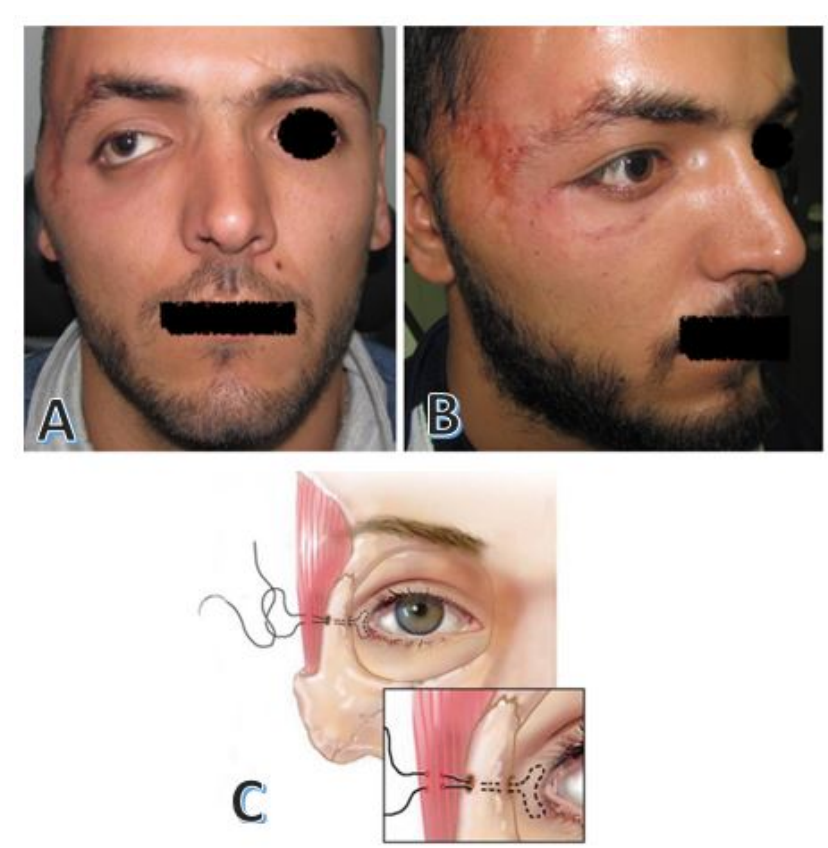

Figure 4: Lateral canthal injury: (A) preoperative images of a 32 year old male one year after his initial injury with lateral canthal dystopia and lower lid retraction (B) Post-operative results after lateral canthal repositioning showing a complete correction of the inferior scleral show; (C) the authors preferred method of lateral canthal support in war injuries by creating a single hole in the thinner part of the lateral orbital wall, posterior to the orbital rim, using an 18-gauge needle and passing a non-absorbable suture which is fixed over the temporalis fascia.

\section{Case 5: Orbital cysts}

The following is a case 22-year-old male presenting 4 week after suffering a blast injury to the right mid-face. The initial management in an outside hospital consisted of globe enucleation followed by immediate upper and lower eyelid skin closure. Three weeks later, the patient developed a cystic structure that drove him to seek specialized medical care (Figure 5A). After 48 hours of intravenous antibiotics, the patient was taken to the operating theater for management. A horizontal skin incision was used to access the cyst (Figure 5B). After adequate identification and anterior dissection, the cyst was opened, and turbid white pus came out. There were no remnants of globe tissues to be found.

Figure 5C shows the inside of the cyst. Again, a small amount of skin and cyst lining was excised. A horizontal skin incision was made from the presumed medial canthal area to the lateral canthal area. The rest of the cyst was kept and used as new socket lining. No orbital implant was inserted. A temporary conformer was placed inside the new socket. A suture was placed to tighten the lower lid laterally (Figure 5D). However, three weeks after the surgery, he presented with sagging of the lower lid. Sagging of the lower lid was most likely due to wound contracture that was exacerbated by the surrounding scarred 
Citation: Abu-Sitta GS, Ma'luf R, Baroud J, Chalhoub R, Hakim C, et al. (2018) Delayed Reconstruction of the Eyelids After War Injuries: Experience from Lebanon (Report of 6 cases). J Trauma Treat 7: 415. doi:10.4172/2167-1222.1000415

Page 4 of 5

tissue. He then underwent a myocutaneous cheek rotation flap with a hard palate graft to support it.

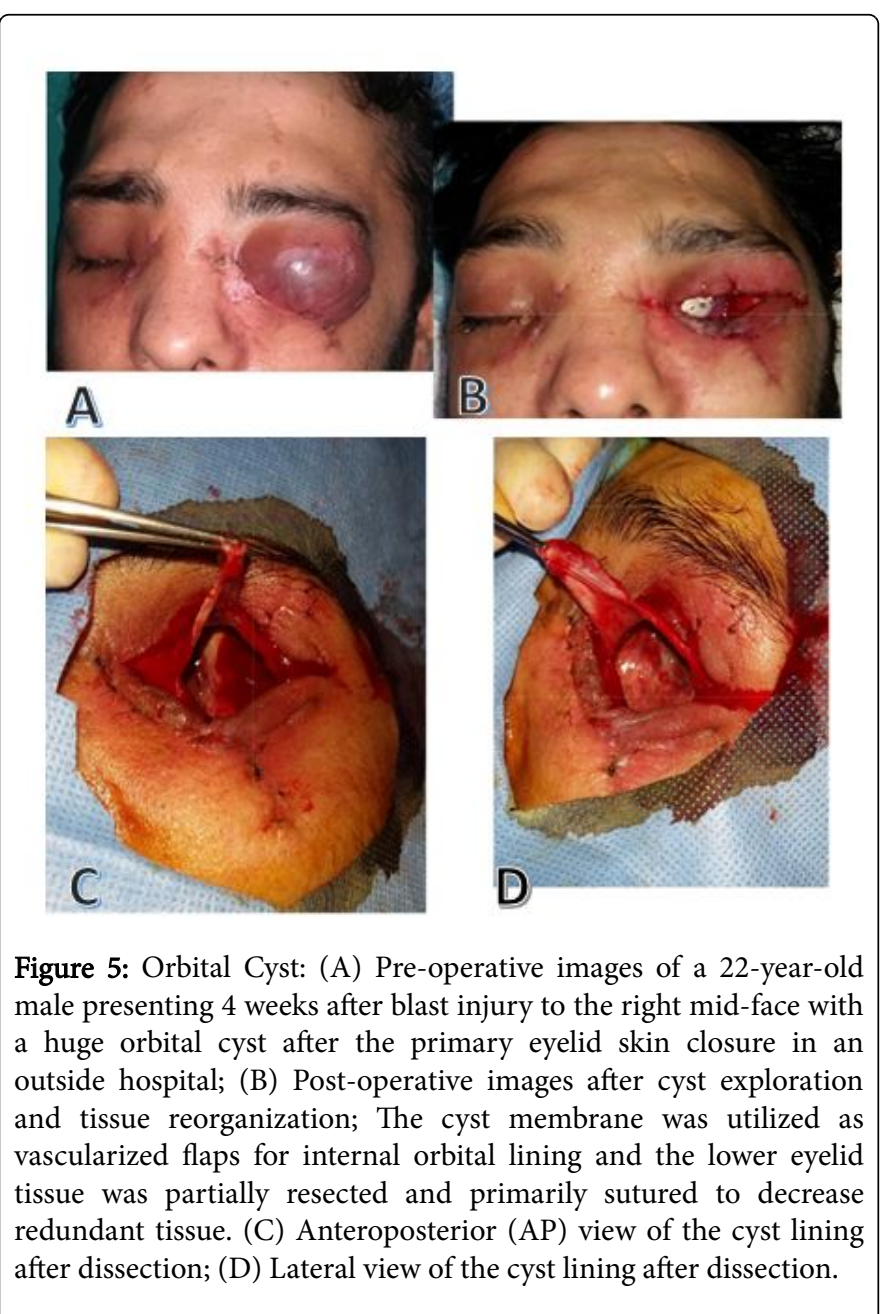

\section{Case 6: Orbital cyst}

A similar example of orbital cyst with its lining used for intraorbital mucosal reconstruction, the cyst in this case was not as large as the previous which allowed adequate lower eyelid recreation without tissue retraction and the need for further flap reconstruction (Figures 6A-6C). A temporary conformer was placed inside the new socket, and an ocular prosthesis was fit after 6 weeks. The lower lid was tight enough to hold the prosthesis and there was no need for a hard graft to support it (Figure 6B). Hyaluronic acid filler was injected into the lateral canthal area, upper and lower eyelids for rejuvenation.

\section{Discussion}

Most of the ocular injuries that we took care of were very extensive, and required an evisceration or enucleation, if not already evacuated with the most primitive methods and with no orbital implants. Some patients presented with complete absence of eyelid tissues and thus the available adjacent skin and subcutaneous tissues were used to reconstruct an eyelid in a way that would allow future fitting with prosthesis.
In facial war reconstruction, we do not have the luxury of choosing our flaps and we usually work around areas of scar tissues to choose the most appropriate and adequately perfused areas, in what we like to call "flaps of opportunity". Rotation flaps, as the ones we used in our cases, are rarely performed in normal circumstances because of obvious cheek scaring, however in this scenario there were no other options due to widespread soft tissue loss and diffuse facial scars, which compromises flap viability.

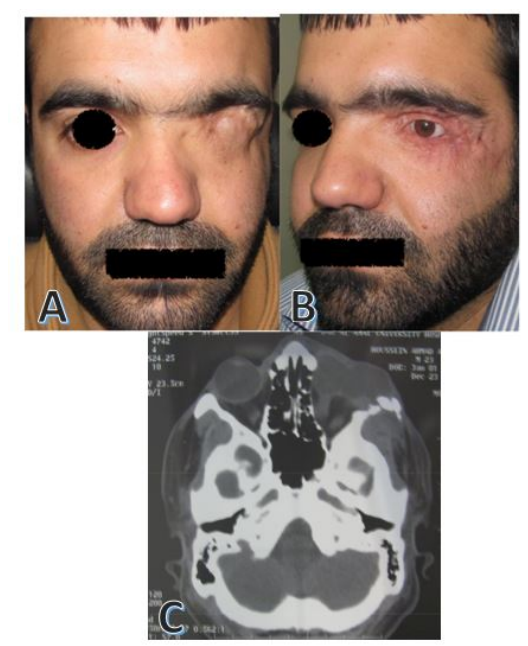

Figure 6: Minor orbital cyst (A) Preoperative images 4 months after initial injury showing the eyelid skin bridging the area from the brow to the cheek. (B) Post-operative images after a horizontal skin incision, cyst wall dissection and utilization to reconstruct the orbital lining (C) Computed Tomography obtained after injury scan revealing an intra-orbital cyst extending from the medial to the lateral orbital rim.

Moreover, in cases of severe foreign body and sharpnel contamination of the wound, it is imperative to avoid hardware placement in the early stages of reconstruction and provide proper antibiotic treatment to allow any infection to subside and decrease the risk of future complications. It is also vital to respect the maxillary and frontal sinuses as violating these sinuses represents a hazard for acquiring an infection. Proper and thorough debridements shoud be performed of all remnant tissue to prevent the formation of cysts or abscesses, similar to the case we presented above which was probably due to residual conjuctival epithelial cells. Nevertheless, any excess tissue, be it a result of a cyst or any other process, should be kept being tailored and trimmed for usage in covering soft tissue defects [10].

In patients presenting with medial canthal dystopia we found it safer to perform our medial canthal suspension as it removes the risk of iatrogenic injury to the contralateral healthy eye. A T-shaped plate for fixation of the medial canthus was another option, however; we tried to use simple techniques with least expensive material possible in all our reconstructive efforts.

Local flap coverage presents a superior color, thickness and texture match compared to free flap transfer in orbital reconstruction [11]. Nonetheless, in war injured patients this might be unattainable as tissues were friable and not easily approximated using sutures, as well as a vague extent of the soft tissue defects. All hardware, plates and 
Citation: Abu-Sitta GS, Ma'luf R, Baroud J, Chalhoub R, Hakim C, et al. (2018) Delayed Reconstruction of the Eyelids After War Injuries: Experience from Lebanon (Report of 6 cases). J Trauma Treat 7: 415. doi:10.4172/2167-1222.1000415

Page 5 of 5

screws, which were placed in the acute setting had to be removed because of exposure due to infection or after debridement.

Our main goal in the reconstruction of those patients was to try to get back structures to their normal anatomical location. The apparent suture line sometimes had to be opened in order to properly reapproximate corresponding structures together. Most of our patients had multiple injuries in the face and body in addition to psychological scarring after their trauma. Hence, they were not asking for perfection, as long as they have a good eyelid and socket structure that allows them to be fit with an artificial eye. Furthermore, an effort is always made to cut down on hospitalization time and fees as much as possible in order to have the sufficient recourses for complete management and discharge. Therefore, plates, screws, and drills were avoided whenever possible.

\section{Conclusion}

Without doubt, proper primary treatment of wounds results in superior aesthetic and functional outcomes. There is no soft-tissue contracture or deformity in primary treatment. In all our patients, physicians or even nurses who lack the proper knowledge in the anatomy of the area did the primary repair in combat zone. Combat hospitals are frequently overwhelmed by casualties and priority is then given to primary wound closure regardless of the anatomical structures that are involved and with total lack of respect to closing the corresponding layers to each other. Lacerated upper and lower lids were sutured together on top of an open eye globe that was left to become phthisical over time. Some of those patients were not medically stable at the time of initial injury, and until the time that they were cleared by the trauma critical care team; wounds have already partly healed by secondary intention.

Last but not least, the task of reconstructing the orbit and the periocular structures should fall on the shoulders of a highly specialized multidisciplinary team to avoid putting patients through a series of traumatizing complications from inadequate primary interventions and treatments.

\section{References}

1. Ueeck BA (2007) Penetrating injuries to the face: delayed versus primary treatment-considerations for delayed treatment. J Oral Maxillofac Surg 65: 1209-1214

2. Covey DC, Peterson DA (1995) Treatment of musculoskeletal blast wounds at a navy field hospital during the Balkans war. Techniques in Orthopaedics 10: 195-205.

3. Abbotts R, Harrison SE, Cooper GL (2007) Primary blast injuries to the eye: a review of the evidence. J R Army Med Corps 153: 119-123.

4. Robson MC, Stenberg BD, Heggers JP (1990) Wound healing alterations caused by infection. Clin Plast Surg 17: 485-492.

5. Francel TJ, Birely BC, Ringelman PR, Manson PN (1992) The fate of plates and screws after facial fracture reconstruction. Plast Reconstr Surg 90: 568-573.

6. Eroglu L, Simsek T, Gumus M, Aydogdu IO, Kurt A, et al. (2013) Simultaneous cheek and lower eyelid reconstruction with combinations of local flaps. J Craniofac Surg 24: 1796-1800.

7. Lee AC, Fedorovich I, Heinz GW, Kikkawa DO (2002) Socket reconstruction with combined mucous membrane and hard palate mucosal grafts. Ophthalmic Surg Lasers 33: 463-468.

8. Elliot D, Britto JA (2004) Tripier's innervated myocutaneous flap 1889. Br J Plast Surg 57: 543-549.

9. Yaremchuk MJ, Chen YC (2009) Bridge of bone canthopexy. Aesthet Surg J 29: 323-329.

10. Motamedi MH, Behnia H (1999) Experience with regional flaps in the comprehensive treatment of maxillofacial soft-tissue injuries in war victims. J Craniomaxillofac Surg 27: 256-265.

11. Ogawa Y, Takemoto T, Suzuki K, Kusumoto K (2011) Application of the lateral orbital flap to reconstruction of the upper and lower eyelids and the eye socket after enucleation. Ann Plast Surg 66: 360-363. 